\title{
GENRES AND TROPES AND THE "PROFILER" TELEVISION SERIES
}

\author{
Ligia TOMOIAG $\breve{A}^{*}$
}

\begin{abstract}
This article is starts from the issue of genre in general - in literature and film - and how views on genre in modern and contemporary criticism have evolved, especially in the past century. Even if many literary critics consider genre a category of the past, readers continue to look for the genre, identify and typify art according to genre, thus influencing especially the cinema and television industry, which not only reflects such interests, but also enriches the field of generic criticism with new tropes all the time. The illustration of this tendency comes from a very special type of detective story: the profiling story, which has been received with much interest by the public, and has given enough material to many critical views. With the iconic The Silence of the Lambs, the story of how psychology can help detectives in identifying and annihilating serial killers, has developed very much, until today, when the newest series, Mindhunter, comes as a kind of prototype 'après la letter'. In fact, this series does not ignite the interest in the genre, nor does it give it a list of generic features, but provides the genre with the necessary historical and social context, as well as with the necessary psychological insights, while presenting the most extraordinary cases of serial killers. The series is more artistic than any of the preceding ones, complicated, appealing to the reader's knowledge of the world and intelligence, as well as to his/her taste.
\end{abstract}

Keywords: genre, tropes, profilers, psychologies, generic prototypes

The discussion on genres in literature and culture started once with the discussion on genres in biology and philosophy in general - especially with ancient philosophers like Plato and Aristotle. In fact, it was Aristotle who tried to contradict Plato, and while giving a general rule for definition, included in it the word genus. In today's world, with all the debates about what is natural, what is biological, what is inherent or constructed, classical Greek and Roman debates, as well as the subsequent ones in the Medieval Times, the Renaissance till the $19^{\text {th }}$ century, can shed some light into the issue of genres, in general, and of cultural and literary genres, especially. The Romantics considered their work too unique to fit into any generic profiles, which seemed to be too fixed in patterns, too static, too classical. Friedrich Schlegel's quote about literary texts as being "a genre unto itself

\footnotetext{
* Assistant Professor PhD, Technical University of Cluj-Napoca, The Baia Mare University Centre, 76 Victoriei Street, Baia Mare (ligiatomoiaga@gmail.com).
} 
(eine Gatung für sich)" (quoted in Duff, 1994), held true for the $20^{\text {th }}$ century new schools of thought and literary criticism, starting with the Russian Formalist Yury Tynyanov, who considered that genres appear and die when they have reached their peak; with Bakhtin and his concept of chronotope, which somehow put together genre and motif; with Keunen's superstructural memory schemata theory; with the social context-related theories of Carolyn Miller, who was influenced by Burke's, Searle's and Austin's New Rhetoric, and who considered that genre is a kind of community response and typified rhetorical actions; with Maurice Blanchot and his argument that forms ceased to exist, and genres have no longer a valid signification (Ion, 1983: 6).

There are many other examples. Nevertheless, such important critics as Tzvetan Todorov continued to give importance to literary genres:

Defining genres implies, thus, establishing a relationship between a-temporal universal archetypes, and historical thematic; without denying that literary genres have a 'natural foundation', as well as a trans-historical one, an existentialist attitude, and an "anthropological structure" [Gilbert Durand], a "mental disposition" [André Jolles] or "an imaginative scheme" [Charles Mauron], Gérard Genette considers that no matter what level of generality we might consider, "the generic fact always combines, inextricably, the fact of nature, and the fact of culture" [Gérard Genette, Introduction...]; there are no archetypes that can totally escape historicity, and still keeping their generic definition; there are modes, for example the story (le récit), there are genres, for instance, the novel." (Ion, 1983: 73, my translation).

To give a list of features, attributes or defining characteristics of genres, according to Durand, Jolles, Mauron, and Genette, we may say that genres are archetypal, thematic, naturally founded, trans-historical, existentialist, anthropological, psychologically disposed. They are linked to our imagination, as well as to nature and culture, they depend on history but also have a trans-historical character. Consequently, they have that kind of permanent value as all aesthetic categories - the beautiful, the ugly, the grotesque, etc. - thus allowing a continuous renewal in terms of the forms genres take, but a perennial quality in terms of ways of telling stories; people still believe in genres, they still consider genres to be relevant, and they also look for those characteristics that derive from the generic definition of stories. Most of the times, when it comes to genres, the critical thought and discussion mostly revolves around lists with typologies, or with the most obvious classifications, with parallels in taxonomic groups, and also with inter-related lists of genres - interdisciplinary versions and types, 
which can use various features coming from culture, philosophy, or sciences, as well as from popular culture.

Northrop Frye started his discussion of genres in his Anatomy of Criticism (1957) from considering their universal range. He named them both genres and modes. Robert Allen, in his turn, view genres as an expression of the critical thinking that tries to give a certain 'scientific' twist to the discussion on literature, while Daniel Chandler considers that the concept was applied on literature from a kind of pre-conceived abstract mode of thinking, when he maintained that genre is "an abstract conception rather than something that exists empirically in the world" (quoted in Feuer, 144). The empirical approach, in which critics attempted at starting the discussion on genre from the particular texts, and work out a typology, showed that there are genres, sub-genres, and even "super-genres" (Foster, quoted in Henke, 371). Such contradictions in the way critics view the issue of genres are very common. Robert Henke referred to disagreements in the issue in a review of an essay on tragicomedy, written by Verna Foster:

...often a disagreement between two critics may be largely traceable to the fact that they come from two different sets of texts. Academic theatre goers (who certainly don't make up the majority of those academics who write about drama), will likely see, within a relatively short time span, plays by Shakespeare, Ibsen, Synge, and Beckett, and they will therefore be interested in commonalities of dramaturgy and audience response between historically disparate works. Historically based critics who publish on drama, such as those associated with new historicism, have 'habits of mind' that are more likely to perceive family resemblances between Shakespeare and Columbus than between Shakespeare and Beckett, and they will likely be suspicious of concepts, assertions, and generic categories that span historical periods. (Henke, 2006: 371).

This quotation argues that there is a difference between writing a historical approach to genres, and experiencing genres directly, by being a theatre lover and going to the theatre where one is exposed to many authors, coming from different historical times, but whose work may display certain common characteristics - especially when it comes to the way they conceived their 'story-telling'. A classical approach to Shakespeare's tragedies might not include such notes as 'soft tragedy', or 'psychological tragedy', considering that such labels are not appropriate to refer to an author of the $17^{\text {th }}$ century. Nevertheless, a contemporary addressee, part of a modern audience, might not consider Romeo and Juliet a 'hardcore' tragedy, or, they may look at Hamlet in Freudian or Jungian terms, more than in Biblical or mythological ones. Contemporary 
critics, like David Bordwell, who refer to genres not only from a literary point of view, but connecting literary genres with cinema genres, show that starting from the theme of the text, one might not find the right genres, as “... any theme may appear in any genre" (Bordwell, 1989: 147).

The discussion on film genres completes and, somehow, motivates new approaches and more comprehensive lists of types and modes. Both Daniel Chandler and Bordwell referred to cinema genres - especially in viewing films according to the period of creation, to technical novelties, to cycles, structure, purpose, tenure, audience, subject and film (Bordwell, quoted in Daniel Chandler). Genre in movies, though, could be referred to from other angles, as well:

While some genres are based on story content (the war film), others are borrowed from literature (comedy, melodrama) or from other media (the musical). Some are performer-based (the AstaireRogers films) or budget-based (blockbusters), while others are based on artistic status (the art film), racial identity (Black cinema), location (the western) or sexual orientation (Queer cinema). (Stam, 2000: 14).

Stam also considers a further approach to genres and their definitions in film theory, which he labels as 'problems': extension problems, normativist problems, monolithic definition problems, and biologist problems. Extension problems appear when the definition and features of a certain genre are stretched, and used in an either too broad sense, or too narrow sometimes there are too many elements of romance in drama, or, on the contrary, there are very few elements of drama in romance...(to put it really simplistically). Normativist issues refer to a critical approach in which the critic only selects those features that 'fit the profile' of the text she has already selected as appropriate, thus making a kind of prescription of the elements a text must contain/or must not contain, if they were to belong to a certain category. In today's light of 'fluid' discourse, it is rather unwise to consider that genres can be monolithic, and that there is just one genre represented in a particular text. Obviously, texts may display certain characteristics of several genres, thus their strict categorization in one or another genre is impossible - especially with contemporary texts. As for the so-called biologist issues, this is a view of genres in Darwinian terms, that is, critics consider genres like cycles of evolution in time. (Stam, 2000: 128129). Swales comes with the idea that attributing genres to texts should take into account the characteristics that are mostly exhibited by a text. Such an approach is considered to be prototypical (Swales, quoted in Chandler, 1997). 
Especially when it comes to the films and serials on TV, the reactions of the public is the most important element to take into consideration, as this particular industry is much more defined and dependant on the reaction of its audience. Daniel Chandler argues that the way the public categorizes texts - be they literary or coming from another artistic realm - continues to be based on their perception of how the story is told, that is, on genres.

How we define a genre depends on our purposes; the adequacy of our definition in terms of social science at least must surely be related to the light that the exploration sheds on the phenomenon. For instance (and this is a key concern of mine), if we are studying the way in which genre frames the reader's interpretation of a text then we would do well to focus on how readers identify genres rather than on theoretical distinctions. Defining genres may be problematic, but even if theorists were to abandon the concept, in everyday life people would continue to categorize texts. (Daniel Chandler, 1997).

It is not easy - considering Chandler's vision on genres - to have the empirical data that might help in determining the audience's/reader's reactions, their preferences, the way they might infer meaning, or make references when it comes to their considering a text as belonging to a certain genre. If the book/film/text is advertised as 'a romance', which elements are there that the reader might consider as extremely important, are indispensible to actually define that text as a 'true romance' story? Much of such defining is, in fact, a matter of satisfied expectations; this is very difficult to put into any kind of system, as they might change in time - as they have - and they might be liable to many personal experiences and to the actual readers' background.

Steve Neale stated that "genres are not systems, they are processes of systematization" (Neale, 51), which might be more suitable a definition when it comes to real texts and real contexts, especially when texts are not 'ideal' and automatic representations of a certain genre, but display characteristics that are relevant for more than one genre. Such evaluation and revaluation of texts from the perspective of genre will also have to take into account their large intertextuality, they depend very much on each other, they will influence each other, and only after such evaluation will they allow labels of any kind.

This process of systematization and labeling should also be put in a historical perspective; some genres are considered to be 'dead', historically dated, some new ones appear, some are evaluated in retrospect and so their defining characteristics are attributed to them in hindsight, while others seem to be 'brand new', or having evolved, thus getting new nuances and new dimensions, some of which have been dormant (Chandler, 1997). 
There are other critics, especially Marxist and feminist ones, who declare that genres are 'dead' and that they are just remains of a patriarchal, supremacist and privileged culture, which make no sense in today's culture.

Strangely, though, no matter how strong the arguments, or how heated the debate, readers of written fiction, or lovers of the cinema and television go on looking for the genre specifications of the texts they buy. When it comes to television, especially, genres have evolved into sub-genres and display such a flourishing of specific tropes, that it makes it rather impossible for critics of the contemporary culture phenomena to overlook such developments.

One such example of generic evolution of a certain theme - because, obviously, a theme and a way of telling the story can evolve into a genre in time - is the 'profiler' film. The first such film in came after the publication of Tom Harris's two novels: Red Dragon (1981), and The Silence of the Lambs (1988). These fictional stories about FBI's profilers and their work could be written after the writer, himself, was allowed to witness BSU meetings, to research their cases and learn about the agents who were taught how to work with the psychological profiles of the criminals, and get insight into their typology.

With the 'launching' of the film The Silence of the Lambs in 1991, the story of profiling on the silver screen or on TV started to be more and more successful and attractive for the large public. If the above mentioned The Silence... was the father of the genre, the 'mother' was the British serial film Cracker (1993-1996), whose flawed and passionate main character is a psychologist able to get into human psyche to a level never experienced before; he is able to understand the criminal, to perceive his/her intentions, routines, deviances and needs. The narrative is double, as, besides the actual criminal narrative, there is the personal story of the protagonist, with a troublesome and complicated family life. The trope of this clash between the life of the profiler at work and his personal life and how they might influence each other sometimes was going to develop in the years to come very much, with such serial films as Millennium (1996-1999), The Profiler (1996-200), Lie to Me (2009-2011), and Criminal Minds (2005- , with a last series being released in 2020, apparently).

Katherine Ramsland, who was specialized in criminal profiling, shows how far such series are from the real work of FBI profilers, as such team are mostly dealing with files, not the criminals per se, they are far from fieldwork, they are out of risk's way, and they do not have the freedom to act upon their conclusions.

On the contrary, they have a strict set of rules, and the detective work is helped by their research, not taken over, or led by them in their private jet plane. Consequently, most of the profiling we may watch on TV has very little correspondence with reality (Ramsland). Her main reference is to 
Chief John Douglas, who after having been one of the first FBI profilers, upon retirement, wrote a book Mind Hunter, which is at the basis of one of the newest profiling television series Mindhunter. Douglas's bestseller made way for this dramatization of the lives of profiling agents in films:

As a result, he became a popular spokesperson, and in Mind Hunter he states "I use a formula, How plus Why equals Who. If we can answer the hows and whys in a crime, we generally can come up with the solution". In other words, based on the idea that people tend to be slaves to their psychology and will inevitably leave clues, a profile is an educated attempt to provide parameters from behavioural evidence at a crime scene that reveal the type of person who committed it. (Ramstad, 2010: 7)

Such is the formula used by writers of the series Profiler, in which the psychological insight of the protagonist is so powerful that it almost has supernatural qualities. Millennium also gives a rather supernatural interpretation to its cases, as the protagonist has mental issues, himself, which allows him to 'penetrate' the criminal minds. The generic tropes of Millennium led the way into another type of profiling, with the theme of 'evil' as main 'protagonist'.

So many episodes of Millennium dealt brilliantly with the idea of "evil" as a concept: of the "End of the World" as a cerebral, intellectual fear. Were we racing to an "apocalypse of our own making?". Were we guaranteed another thousand years, and if so, would it be the "same old crap?". Yet what makes [it] so special is the fact that [here] evil boasts a beguiling and very human form, simultaneously repellent and attractive. This is sort of perfect expression of the Gothic aesthetic. [...] Millennium was so ahead of its time in about a million ways. Back in the 1990s, it featured stories on avian flu-type bugs [...], stem cell research [...], the Human Genome Project [...], end-of-life issues [...], the Y2K threat $[\ldots]$ and other stories that would come to dramatically affect the $21^{\text {st }}$ century [...]. (Muir, 2005)

Muir does not only praise Millennium for its contribution to the profiling genre, but also for it contribution in leading other themes and tropes, which would be used in $21^{\text {st }}$ century series. He also underlines the generic and aesthetic link between contemporary serial films and the $19^{\text {th }}$ century gothic. Nevertheless, the team of profilers had a very successful exemplification in Criminal Minds, a series that has gathered much appreciation in its 14 seasons. The series is based on FBI profiling team tradition, but it also comes with many storylines, and with a team that is made up of different 
experts with different world-views, and with different and important contributions in the profiling of serial killers. The team has an FBI 'fearless' investigator and detective, who is trained in psychological profiling, as well; then, there is the computer wizard, a former hacker, who is also a kind of 'flower-power' type of personality; then, there is the genius doctor, who has several Ph.D.'s and who has eidetic memory; the linguist is also very important, as she can interpret people's speech and their texts and go beyond the surface of the words into the meaning behind; last, but not least, there is a communication expert, who is also very compassionate, very intelligent and brave. Such a team is, obviously, too good to be true. Still, the series convinced mainly due to this team, and due to the very serious research of the writers, who were able to come with extremely challenging and accurate portraits of serial killers. Sometimes, though, the temptation to show such individual as more powerful than they really are is luring the writers and getting them too excited and rather off-beat, but mostly the story is well-conducted.

The genre, even if very new, came with many tropes and ideas that established it as iconic. One of the most important such tropes - which influenced other shows, as well - was the 'preventing of the crime', by the ability of the team to discover the identity of the criminal before his/her committing yet another murder. Moreover, the 'personal' stories of the characters are well-articulated and compelling narratives, which provide not only side-stories, but explain the reactions and capabilities of the profilers. More than other such shows, Criminal Minds also convinces with its stories of the serial killers, their motifs and reactions.

The writers of the show seem to come with wellarticulated stories of serial killers, whose motifs and reactions, be they cruel and definitely difficult to watch, are well-justified in almost each episode and, therefore, palatable. The show is recommended by the story's good balance between police action and thought, humane relations and abnormality, violence and rational vision (the literary and philosophical quotes at the end of each episode are inspired and bring an air of intellectuality to the serial film). (Tomoiaga, 2019: 43)

As with most serial films on TV, the personal stories of the main protagonists try to represent and refer to common social aspects and beliefs. Besides the propagandistic inclination of the show - more or less, all American series try to 'speak' in favor of a vision on life and mirror the most important discussions and attitudes of their time - which are reflected in the main characters, the show has well-constructed characters, their personal data, their biographies are relevant: one character is a single 
mother, and that is very difficult to handle when one is an FBI agent; another character is a 'survivor' of many marriages, and discovers very late in life the joy of fatherhood; the tough, fit and attractive detective was an orphan, and he was abused as a child; the main commanding officer has a family but has no time for it, and his work gets his wife killed; the genius of the group has a story of mental illness, his mother is in an asylum with schizophrenia, and he is fearful he might have inherited the condition etc. Such stories help the audience identify and believe the show, as the heroes are not necessarily endowed with special characteristics and care-free lives; on the contrary, their successes are due to their hard and committed work, and their personal lives are like everybody else's lives.

The profilers' jobs, though, depend mostly on the cases they try to solve, and the crimes they try to prevent. It is of utmost importance for such shows to beat the predictable, and propose new and interesting cases all the time. Such work entails not only talent and imagination on the part of the writers of the show, but very serious and committed research. For 14 seasons - and with a $15^{\text {th }}$ upcoming - this show has improved its case study and storyline very much. Even if some critical views considered that the personal lives of the characters interfere too much with the way they handle cases, which in 'real life' does not happen, the fandom of the show considers that this is one of the qualities of the story: in fact, all people are more or less influenced in their professional lives by their personal experience and background.

Intelligence, as well as social and psychological data, come flying from all directions from characters on the team - all have their specialty, including a young authority with a genius-level I.Q. (Matthew Gubler) obligingly presented, in accordance with televisions norm, as a social geek. The team is deep into quotes that fly around with the speed of bullets [...]. In addition to all else, the aspect of Criminal Minds that's seriously gratifying is its total absence of psychic-detective claptrap - seers who solve murders where police cant' because of supernatural powers. This show's focus is on heroes whose primary weapons are learning and reason. [...] From the evidence of the first few episodes, Criminal Minds may be a hit, and deservedly. (Rabinowitz, 2005)

To return to Ramstad and Chief Douglas, and to the entire genre of the profiling story, after so many episodes of profiling detective work, the audience and the writers felt the need to go back to the history of profiling, to the initial book written by Douglas, Mind Hunter. In a way, we may consider that the prototype of the genre in terms of its 'real life' content and reference, as well as in terms of the objective portrayal of such a professional, only came after its avatars! Even if cinematically speaking The Silence of the Lambs can be considered to be the source and inspiration of 
such films and series, the profiling profession is best illustrated by the latest series, which bears the title of Douglas's book, Mindhunter. This is a strange case of the prototype coming 'after' the avatars, but the need for a historical view on the profession was felt by many. To write such a film is really difficult, as historical backgrounds and events can be ruining the rhythm of the episodes.

Then, it is a construction in which the 'reality' of the times has to be very well represented, but not prevent the show from being interesting and attracting modern viewers. Another issue refers to the very subject of the series and the blending of 'old' mentalities and 'new' attitudes both in the professional and in the private lives of the characters. The writers of the show Mindhunter, Chief John Douglas, himself, together with Mark Oshaker, and the actual creator of the show, Joe Penhall, joined forces with a team of directors, mainly coming from the cinema industry: David Fincher, Carl Franklin, Andrew Douglas, Asif Kapadia, Tobias Lindholm and Andrew Dominik. The latter four only contributed to the first two episodes, just to get the series started, and to convince the audience to go on watching, which they did, due to the efficient manner they go back to the early 70's and their social background. The rhythm of the film might be slower than usual, there are very many words, most of the time characters discuss, many scenes are almost black and white, mentalities are old and some frighteningly dated.

The FBI of the times, as well as the police were much different from today. The stories of the agents, themselves, motivate their actions to a certain degree. What is remarkable, though, is that balance between all of the above: even starting with the first two episodes the series is compelling, even if nothing seems to be extraordinary, except the stories of the serial killers, themselves. There are no violent scenes, very few images with the horrible murders, but the atmosphere created around the penitentiaries, themselves, and the killers keeps the interest of the audience high.

The opening hours, directed by Fincher, are fascinating, even while they're in no hurry to tell the origin story of the FBI profiler. There are a couple of montages in particular that are beautifully assembled, showing the two agents trying to teach their theories to local police who, for the most part, are resistant to them. (Binaculli, 2017)

It is unusual, to say the least, for an American series to be nonpropagandistic and non-ideological, but with Mindhunter there is very little propaganda.... This is what attracts most: it is a historical film - much of what is presented is historically accurate (the beginning of profiling at the FBI, relations and politics within the FBI, the police etc., the way people saw mental illnesses and the role of psychologists, as well as race issues, 
misogyny, biases of all kinds, as well as some of the serial killers, themselves); it is a psychological film, in which both the changing of times in terms of how psychology managed to clarify certain issues referring to criminal and crimes, and the very understanding of serial killers are presented. At the same time, the creators of the show resist the very fashionable temptation to label and judge the 'misconducts' and 'political incorrectness' of the times, even if there are scenes that are startling from this point of view.

But Mindhunter avoids the trap of other dramas, which seem overly concerned with upbraiding the past for failing to live up to the politically correct ideals of the 20th century. It's not tutting at the bad old days so much as presenting the intellectual wrangling that saw police psychologists rise from back-room boys to star players in major criminal investigations. (Lawrence, 2017)

Sexual liberation, new family relations, the issue of adoption, child abuse and child protection, loneliness, sexual preferences, freedom of speech (the FBI takes down a few taboo words from their 'list' almost every episode), conditions in the detention establishments, internal politics in the FBI and the police, reporters and the press, all these and many others are present, but their presence require a keen eye on the part of the audience, as they are very artfully intertwined with the main story: the psychology of crime and the way profilers can find the motivation of the murderers in their attempt to catch the killers, and even to prevent other tragedies from happening.

Under the direction of Fincher (returning to television for the first time since his triumphant House of Cards), there is an unshowy, meticulous cinematic quality that draws you in, irresistibly, to its pale-brown world of desk jobs and smoky cinemas. (Lawrence, 2017)

We may consider, therefore, that this is a kind of 'prototype' of the profiler detective story, as it gives all the explanations of how the behavioral unit started its activity, the cases it drew its 'knowledge' from, the importance of psychology in determining the typology of the killers, the relations between institutions in solving such cases, as well as the impact the cases have on the detectives and their lives. It is impossible to be in the presence of serial killers, some of whom are very intelligent and manipulative, and not be influenced by such encounters. The profiling serial films have now a kind of matrix, even if it came not 'avant la lettre' but 'après la lettre'. It also sets a high standard of artistic accomplishment, which enables the genre to gain more tropes, and also a more serious status. It is one of the series that does not compromise in terms of pace and action 
just to satisfy a rather superficial audience, but trusts its audience to be intelligent, insightful and attentive at all details.

\section{Works Cited:}

Binaculli, David, FBI Profilers Pursue Serial Killers And Their Motives In 'Mindhunter'

October 12, 2017, https://www.npr.org/2017/10/12/557328890/fbi-profilerspursue-serial-killers-and-their-motives-in-mindhunter?t=1572857908763

Bordwell, David. (1989). Making Meaning: Inference and Rhetoric in the Interpretation of Cinema. Cambridge, MA: Harvard University Press.

Chandler, Daniel. (1997). An Introduction to Genre Theory. Available online at: http.//www.aver.ac.uk/media/Documents/intgenre/intgenre8.html [20.11.2018].

Duff, David. (2000). Modern Genre Theory. Harlow: Pearson

Feuer, Jane. (1992). "Genre study and television". In Robert C. Allen (ed):

Channels of Discourse, Reassembled: Television and Contemporary Criticism. London: Routledge, pp. 138-59

Henke, Robert. (2006), "Review of The Name and Nature of Tragicomedy, by Verna A. Foster", in Comparative Drama: Vol. 40; Iss.3, Article 5, available online at: https://scholarworks.wmich.edu/compdr/vol40/iss3/5/ [August, 28, 2019]

Lawrence, Ben. Mindhunter, episode 1 review: the most accomplished drama on TV right now The Telegraph, 13 OCTOBER 2017,

https://www.telegraph.co.uk/on-demand/0/mindhunter-episode-1-reviewaccomplished-drama-tv-right-now/ [October, 17, 2019]

Ion, Angela. (1983). 'In cautarea surselor profunde ale povestirii', Preface to Romanul inceputurilor si inceputurile romanului, transl. by Angela Ion. Bucuresti: Univers

Muir, John Kenneth. (2005). "Friday Retro-TV flashback \#10: Chris Carter's Millennium: The Lucy Butler Trilogy", at John Kenneth Muir's Reflections on Cult Movies and Classic TV, available online at: http://reflectionsonfilmandtelevision.blogspot.ro/ [July 23, 2019]

Neale, Stephen. (1980). Genre. London: British Film Institute [solely concerned with film]; an extract can be found in Tony Bennett, Susan Boyd-Bowman, Colin Mercer \& Janet Woollacott (eds.) (1981). Popular Television and Film. London: British Film Institute/Open University Press.

Rabinowitz, Dorothy. (2005). "Circle of Genius", in "The Wall Street Journal", October 7, 2005, available online at: http://www.wsj.com/ [July 15, 2019]

Ramsland, Katherine. (2010). "Introduction", to The Forensic Psychology of Criminal Minds, New York: Berkeley Boulevard

Stam, Robert. (2000). Film Theory. Oxford: Blackwell.

Swales, John. (1990). Genre Analysis. Cambridge: Cambridge University Press

Tomoiaga, Ligia. (2019). Television Series as Mirrors of Contemporary Life, Newcastle upon Tyne: Cambridge Scholars Publishing 